\title{
CONSÓRCIO MILHO-BRAQUIÁRIA COM DENSIDADES POPULACIONAIS DA FORRAGEIRA NO CENTRO-SUL DO BRASIL
}

\author{
GESSÍ CECCON¹, JUSLEI FIGUEIREDO DA SILVA², \\ PRISCILA AKEMI MAKINO² e ANTONIO LUIZ NETO NETO²
}

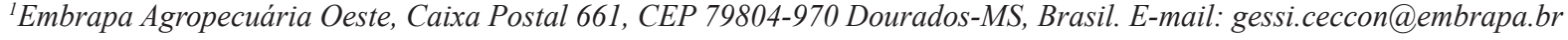
${ }^{2}$ Universidade Federal da Grande Dourados (UFGD), Faculdade de Ciências Agrárias,

Rodovia Dourados-Itahum, km 12, CEP 79804-970 Dourados-MS, Brasil.

E-mail: jusleifigueiredo@hotmail.com,priscila_akemi17@hotmail.com,aln_neto@hotmail.com
\end{abstract}

Revista Brasileira de Milho e Sorgo, v.17, n.1, p. 157-167, 2018

\begin{abstract}
RESUMO - O trabalho foi realizado com o objetivo de avaliar a produtividade de grãos e de massa de milho, solteiro e consorciado com populações de plantas de duas espécies de Brachiaria para formação de palha ou pasto. Utilizou-se o delineamento experimental em blocos ao acaso, com parcelas subdivididas e quatro repetições. As parcelas principais foram constituídas pelas espécies de Brachiaria (Brachiaria brizantha cv. Marandu e Brachiaria ruziziensis) e as subparcelas, pelas populações de Brachiaria $\left(0,5,10,20\right.$ e 40 plantas $\left.\mathrm{m}^{-2}\right)$, em linhas espaçadas de $0,45 \mathrm{~m}$. Os tratamentos consorciados apresentam maior acúmulo de massa seca total do que o milho em cultivo solteiro. O máximo rendimento total de massa seca foi observado entre 10 e 12 plantas $\mathrm{m}^{-2}$ de B. ruziziensis, mas com maiores populações de plantas de $B$. brizantha. A produtividade de grãos teve redução linear de $13,39 \mathrm{~kg} \mathrm{ha}^{-1}$ por planta $\mathrm{m}^{-2}$ de $B$. brizantha e redução quadrática média de $42,04 \mathrm{~kg} \mathrm{ha}^{-1}$ por planta $\mathrm{m}^{-2}$ de $B$. ruziziensis.
\end{abstract}

Palavras-chave: Zea mays, Urochloa, cultivo consorciado, plantio direto.

\section{INTERCROPING MAIZE-BRACHIARIA WITH FORAGE PLANT POPULATION IN THE MID-SOUTH OF BRAZIL}

\begin{abstract}
The objective of this study was to evaluate the grain and dry matter yield of maize, sole and intercropped with four plant populations of two Brachiaria species. We used the experimental design of randomized blocks, with split plots and four replications. The main plots consisted of the Brachiaria species [Brachiaria (sin. Urochloa) brizantha cv. Marandu and Brachiaria ruziziensis] and subplots consisted of the Brachiaria populations $(0,5,10,20$ and 40 plants $\mathrm{m}^{-2}$ ), in same lines spaced $0.45 \mathrm{~m}$. The intercrop treatments have higher total dry matter accumulation than maize monocrop. The maximum total yield dry mass was observed between 10 and 12 plants $\mathrm{m}^{-2}$ B. ruziziensis,

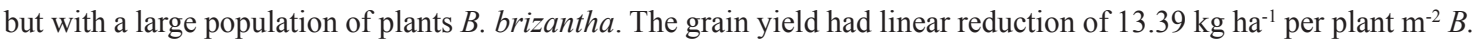
brizantha and average quadratic reduction of $42.04 \mathrm{~kg} \mathrm{ha}^{-1}$ per plant $\mathrm{m}^{-2}$ of B. ruziziensis.
\end{abstract}

Keywords: Zea mays, Urochloa, intercrop, cropping systems, no tillage. 
O Sistema Plantio Direto tem se consolidado ao longo dos anos como uma técnica viável e produtiva nos sistemas agrícolas, e muitos estudos têm investigado alternativas para manutenção das premissas desse sistema de produção.

O cultivo consorciado de milho com braquiária é uma oportunidade para aumentar a produtividade de milho e de soja, na rotação/sucessão (Ceccon et al., 2014), sem aumento de área. Este sistema de cultivo apresenta melhoria nas propriedades químicas e físicas do solo (Amado et al., 2007) e supressão de plantas daninhas (Concenço et al., 2013). As melhorias ocorrem pela presença de palha e raízes da forrageira, que contribuem para a menor oscilação da temperatura (Ceccon et al., 2009) e maior atividade da macrofauna do solo (Marchão et al., 2007). Neste sistema, ocorre maior acúmulo de massa de elevada relação $\mathrm{C} / \mathrm{N}$ sobre a superfície do solo com maior persistência (Perin et al., 2004; Andreola et al., 2000), e consequente maior aporte de nutrientes a serem liberados no solo.

Em baixas populações de plantas, a forrageira proporciona adequada quantidade de massa para cobertura do solo (Ceccon et al., 2014). Em altas populações de plantas, após a colheita do milho, a braquiária, principalmente $B$. brizantha pode ser utilizada como pastagem por causa da maior produtividade de forragem em função do maior número de plantas. As condições ambientais podem interferir no desenvolvimento das duas espécies, principalmente em cultivo no período de outono-inverno, quando há redução de temperatura, luz e umidade. Estudos relatam que a produtividade do milho pode ou não ser afetada pela presença da forrageira (Borghi \& Crusciol, 2007; Resende et al., 2008), podendo inviabilizar o cultivo em consórcio. A modalidade de cultivo (Brambilla et al., 2009), o período de semeadura e a população de plantas (Ceccon et al., 2009) são fatores que podem ser ajustados para diminuir ou eliminar a competição entre as duas espécies.

Objetivou-se avaliar a produtividade de grãos e de palha de milho safrinha consorciado com populações de plantas de Brachiaria brizantha (sin. Urochloa brizantha) cv. Marandu para formação de pasto e de Brachiaria ruziziensis (sin. Urochloa ruziziensis) para formação de palha, em quatro ambientes da região Centro-Sul do Brasil.

Os experimentos foram implantados nas seguintes localizações e datas: Dourados-Mato Grosso do Sul (MS) (22 $13^{\prime} \mathrm{S}$ e $54^{\circ} 48^{\prime} \mathrm{W}, 400 \mathrm{~m}$ de altitude, em 01/03/12), São Gabriel do Oeste-MS (22 ${ }^{\circ} 25^{\prime} \mathrm{S}$ e 55³2' W, 632 m, em 24/02/12), Naviraí-MS (2314' $\mathrm{S}$ e $54^{\circ} 10^{\prime} \mathrm{W}, 377 \mathrm{~m}$, em 06/03/12) e Floresta-Paraná $(\mathrm{PR})\left(23^{\circ} 35^{\prime} 49^{\prime \prime} \mathrm{S}\right.$ e $52^{\circ} 04^{\prime} 12^{\prime}$ ' W, $388 \mathrm{~m}$, em 07/03/12). O solo foi classificado como Latossolo Vermelho distroférrico em Dourados-MS e Floresta -PR e como Latossolo Vermelho distrófico em Naviraí -MS e São Gabriel do Oeste-MS (Santos et al., 2013).

A distribuição de chuvas durante o cultivo do milho foi de $556 \mathrm{~mm}$ em Floresta-PR, $405 \mathrm{~mm}$ em São Gabriel do Oeste-MS, 552 mm em Dourados-MS e 205 mm em Naviraí-MS. Em 08/06, foram registradas temperaturas médias mínimas de $10{ }^{\circ} \mathrm{C}$ em Dourados e de $8{ }^{\circ} \mathrm{C}$ em Naviraí, quando o milho já havia completado o ciclo, enquanto a maior média das temperaturas máximas foi de $28{ }^{\circ} \mathrm{C}$ em Naviraí, em $13 / 03$. Não houve período de estiagem prolongada ou com baixas temperaturas que comprometessem a produtividade do milho nos quatro ambientes (Instituto Nacional de Meteorologia, 2017).

O delineamento experimental foi em blocos ao acaso com parcelas subdivididas em parcelas de sete linhas de 0,45 m entre si, com $12 \mathrm{~m}$ de comprimento, em quatro repetições. As parcelas principais 
foram constituídas pelas espécies de Brachiaria ( $B$. brizantha cv. Marandu e B. ruziziensis) e as subparcelas, pelas populações de plantas de Brachiaria (0, 5, 10, 20 e 40 plantas $\mathrm{m}^{-2}$ ). As populações de plantas de braquiária foram ajustadas mediante o teste de germinação realizado em substrato de areia e a quantidade de sementes calculada de acordo com Ceccon (2015).

A semeadura do milho híbrido de ciclo precoce BRS 1010 foi realizada com semeadora equipada com disco de corte frontal, haste sulcadora para distribuição de $220 \mathrm{~kg} \mathrm{ha}^{-1}$ de adubo NPK 08-20-20 em todas as parcelas e disco duplo desencontrado para posicionamento das sementes, com população média de 50 mil plantas $\mathrm{ha}^{-1}$. A semeadura da braquiária foi realizada na mesma data e linhas do milho, a uma profundidade de 4 a $5 \mathrm{~cm}$, utilizando semeadora marca Wintersteiger, modelo Plotseed TC (Wintersteiger, 2014).

O controle de plantas daninhas foi realizado mediante a dessecação da área em pré-semeadura, na dose de 1,44 $\mathrm{L} \mathrm{ha}^{-1}$ de equivalente ácido de glifosato e durante a condução do experimento realizou-se mais uma aplicação do herbicida atrazina na dose de 1,5 $\mathrm{kg} \mathrm{ha}^{-1}$ de ingrediente ativo, em pós-emergência do milho e das plantas daninhas.

As pragas foram controladas mediante o tratamento das sementes de milho com inseticida thiodicarbe, na dose de $0,02 \mathrm{~L} \mathrm{~kg}^{-1}$ de semente, e as sementes de braquiária foram tratadas com inseticida fipronil na dose de $0,002 \mathrm{~L} \mathrm{~kg}^{-1}$ de semente, mais uma aplicação de inseticida deltametrina na dose de 0,005 $\mathrm{kg} \mathrm{ha}^{-1}$ aos dez dias após a emergência das espécies.

Na maturação fisiológica do milho avaliou-se a altura de plantas de milho, da base do solo até a base da folha bandeira, e de braquiária foi considerada altura da base do solo até as pontas médias das maiores plantas. Na colheita do milho, foram coletadas e trilhadas as espigas de duas linhas centrais de cada par- cela. Foi realizada pesagem de grãos e massa de 100 grãos e calculada a produtividade a $13 \%$ de umidade.

$\mathrm{O}$ rendimento de massa foi avaliado através do corte e da pesagem de cinco plantas de milho e as plantas de braquiária foram contidas em um metro de linha, com população previamente ajustada aos 10 dias após a emergência. As plantas foram cortadas rente ao solo e uma subamostra foi seca em estufa com circulação forçada de ar a $60{ }^{\circ} \mathrm{C}$ por 72 horas para determinação da massa seca.

Os dados foram submetidos à análise de variância (ANOVA) em cada local e depois foi realizada a análise conjunta. Quando significativas, as médias de espécies e locais foram comparadas pelo teste de Tukey $(\mathrm{p}<0,05)$. Para médias de populações de plantas de braquiária realizou-se a análise de regressão polinomial, adotando-se o modelo de melhor ajuste $(\mathrm{p}<0,05)$, utilizando-se o programa estatístico SISVAR (Ferreira, 2011).

A análise de variância apresentou efeito simples dos fatores para todas as variáveis analisadas; interação significativa entre local e espécie para as avaliações realizadas no milho e na altura de plantas de braquiária; interação significativa entre local e população para rendimento de massa de braquiária; interação significativa entre espécie e população para rendimento total de massa; e interação tripla entre local, espécie e população para rendimento de massa de braquiária e rendimento de massa seca total.

Quanto à altura das plantas de Brachiaria (Tabela 1), verificou-se maior altura de plantas em Floresta e Dourados, no entanto Dourados não diferiu estatisticamente de Naviraí e São Gabriel do Oeste. Para a B. ruziziensis, observou-se maior altura de plantas em Dourados, comparativamente aos demais ambientes avaliados, sendo também superior em relação à $B$. brizantha nesse ambiente. 
Tabela 1 - Altura de plantas de Brachiaria e produtividade de grãos de milho, no consórcio de milho safrinha com Brachiaria brizantha cv. Marandu e B. ruziziensis em quatro ambientes.

\begin{tabular}{|c|c|c|c|c|}
\hline & Dourados & Floresta & Naviraí & São Gabriel do Oeste \\
\hline Espécie & \multicolumn{4}{|c|}{ Altura de plantas (m) } \\
\hline B. brizantha & $1,40 \mathrm{bAB}$ & $1,46 \mathrm{aA}$ & $1,34 \mathrm{aB}$ & $1,34 \mathrm{aB}$ \\
\hline B. ruziziensis & $1,64 \mathrm{aA}$ & $1,45 \mathrm{aB}$ & $1,37 \mathrm{aB}$ & $1,37 \mathrm{aB}$ \\
\hline C.V. parcela $(\%)$ & & & 5,5 & \\
\hline C.V. subparcela $(\%)$ & & & 6,8 & \\
\hline \multirow[t]{2}{*}{$\underline{\text { Resíduo }}$} & & & 12,2 & \\
\hline & \multicolumn{4}{|c|}{.......... Produtividade de milho safrinha $\left(\mathrm{kg} \mathrm{ha}^{-1}\right)$........... } \\
\hline B. brizantha & $5.653 \mathrm{aB}$ & $5.650 \mathrm{bB}$ & $5.231 \mathrm{aB}$ & $8.109 \mathrm{aA}$ \\
\hline B. ruziziensis & $5.188 \mathrm{bC}$ & $6.059 \mathrm{aB}$ & $4.564 \mathrm{bD}$ & $7.430 \mathrm{bA}$ \\
\hline C.V. parcela $(\%)$ & & & 11,43 & \\
\hline C.V. subparcela $(\%)$ & & & 8,01 & \\
\hline Resíduo & & & 9,51 & \\
\hline
\end{tabular}

Médias seguidas de mesma letra, minúscula na coluna e maiúscula na linha, não diferem entre si pelo teste de Tukey ( $\mathrm{p}<0,05$ ).

A produtividade de grãos de milho (Tabela 1) foi superior em São Gabriel do Oeste, independentemente da forrageira utilizada. No entanto, $\operatorname{com} B$. brizantha no consórcio não houve diferença estatística para a produtividade entre os demais ambientes (Dourados, Naviraí e Floresta), mas para B. ruziziensis observou-se resposta diferenciada com produtividade superior em São Gabriel do Oeste seguida por Floresta, Dourados e Naviraí. Na comparação entre as forrageiras, nota-se que há diferença estatística nos quatro ambientes com maior produtividade de grãos de milho no consórcio com $B$. brizantha, exceto em Floresta.

A interferência das forrageiras no estado nutricional da cultura e na produtividade de grãos em sistemas de consórcio depende das condições de solo, clima, espécies utilizadas e do manejo empregado (Cruz et al., 2009).

Para a altura de plantas de milho houve redução linear em função do aumento da população de
Brachiaria na linha (Figura 1). Entretanto, esta variação é de ordem pequena, pois de acordo com o modelo matemático estima-se uma redução de 0,0014 $\mathrm{m}$ na altura das plantas de milho para cada planta de Brachiaria adicionada ao consórcio.

Brambilla et al. (2009) observaram diferenças na altura de plantas de milho no espaçamento reduzido, com maior altura no cultivo solteiro em relação ao consórcio com $B$. ruziziensis, na população proveniente de $8 \mathrm{~kg} \mathrm{ha}^{-1}$ de sementes, na mesma linha de semeadura. Os autores evidenciam que sem a presença da forrageira o milho aproveita melhor luz, água e nutrientes.

A maior altura de plantas de Brachiaria foi verificada no consórcio com população de 37 plantas $\mathrm{m}^{-2}$ (Figura 1). No consórcio com baixas populações de Brachiaria (5 e 10 plantas $\mathrm{m}^{-2}$ ) o milho exerce maior domínio, pois este cresce e se desenvolve primeiro levando a uma supressão da forrageira principalmente pelo efeito do sombreamento (Jakelaitis et al., 2006). 


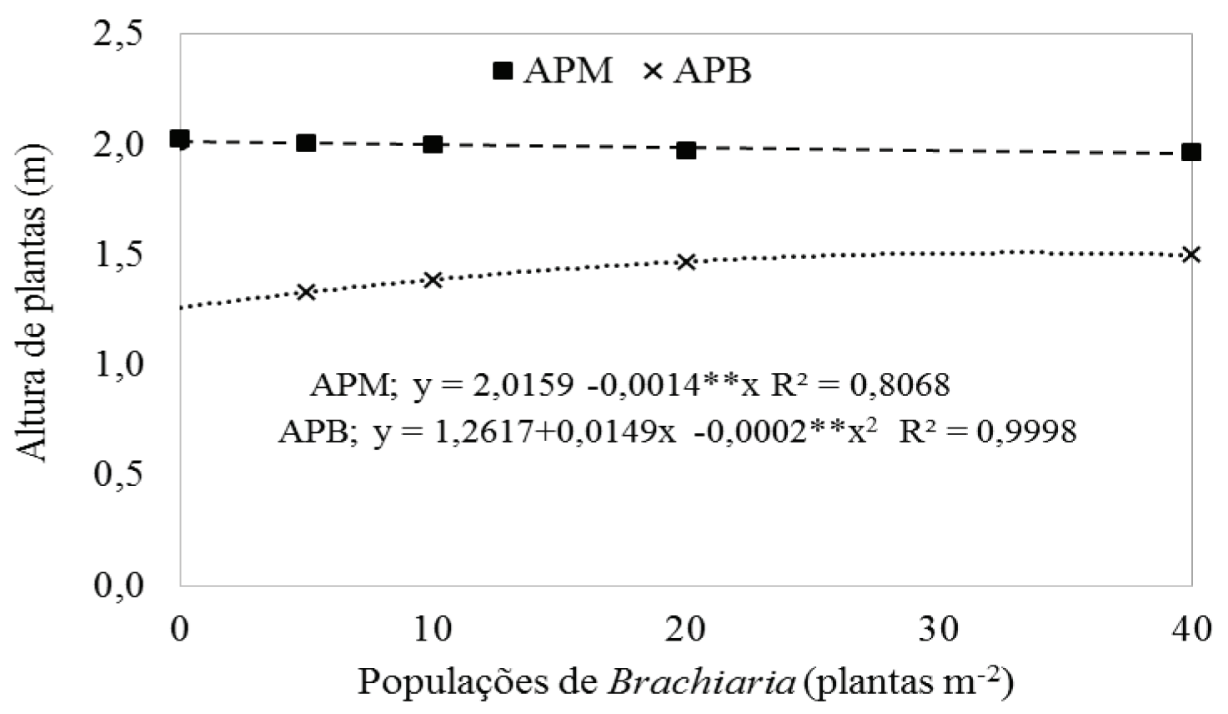

Figura 1 - Altura de plantas de milho (APM) e altura de plantas de Brachiaria (APB) no consórcio de milho safrinha com populações de Brachiaria, em espaçamento reduzido. Médias de Dourados, Floresta, Naviraí e São Gabriel do Oeste. $* *(p<0,01)$.

O rendimento de massa seca de Brachiaria (RMB) foi influenciado pelos ambientes e pela espécie forrageira (Figura 2). Em Dourados, Floresta e Naviraí houve aumento linear no rendimento de massa seca em função do incremento na população de plantas de Brachiaria, sendo este rendimento mais elevado quando se utilizou a B. ruziziensis (Figura 2A, B e C). Em São Gabriel do Oeste (Figura 2D) também se observou aumento linear no rendimento de massa seca da $B$. brizantha, o que não ocorreu para a $B$. ruziziensis, de forma que essa última apresentou maior rendimento de massa $\left(4.350 \mathrm{~kg} \mathrm{ha}^{-1}\right)$ na população de 26 plantas $\mathrm{m}^{-2}$.

As plantas de milho promovem o sombreamento e competem pelos recursos do meio com a forrageira, suprimindo o seu crescimento e consequente acúmulo de biomassa de matéria seca. Segundo Paciullo et al. (2011), sob restrição de luminosidade há uma redução na produção de perfilhos pelas forrageiras favorecendo os perfilhos já existentes.
Na Figura 3, são apresentados os resultados para o rendimento de massa seca de milho (RMM) em função das espécies e dos ambientes. Em Dourados e Naviraí (Figura 3A e C) observou-se redução linear no acúmulo de massa seca à medida que havia mais plantas de Brachiaria na linha de semeadura, independentemente da espécie forrageira utilizada. Entretanto, nesses dois locais a $B$. brizantha proporcionou maior acúmulo de RMM em comparação a B. ruziziensis. Em Floresta e São Gabriel do Oeste (Figura 3B e D) não houve efeito significativo de espécie e população para a $B$. brizantha, mas para a $B$. ruziziensis, em Floresta, houve redução linear com o aumento na população de plantas, e em São Gabriel do Oeste, o mínimo acúmulo de massa seca foi verificado com 32 plantas $\mathrm{m}^{-2}$ de $B$. ruziziensis.

$\mathrm{O}$ rendimento total de massa seca (RTM), constituído pelo somatório de massa seca de milho e de Brachiaria, foi influenciado pelas populações das espécies forrageiras e ambientes (Figura 4). Apenas 

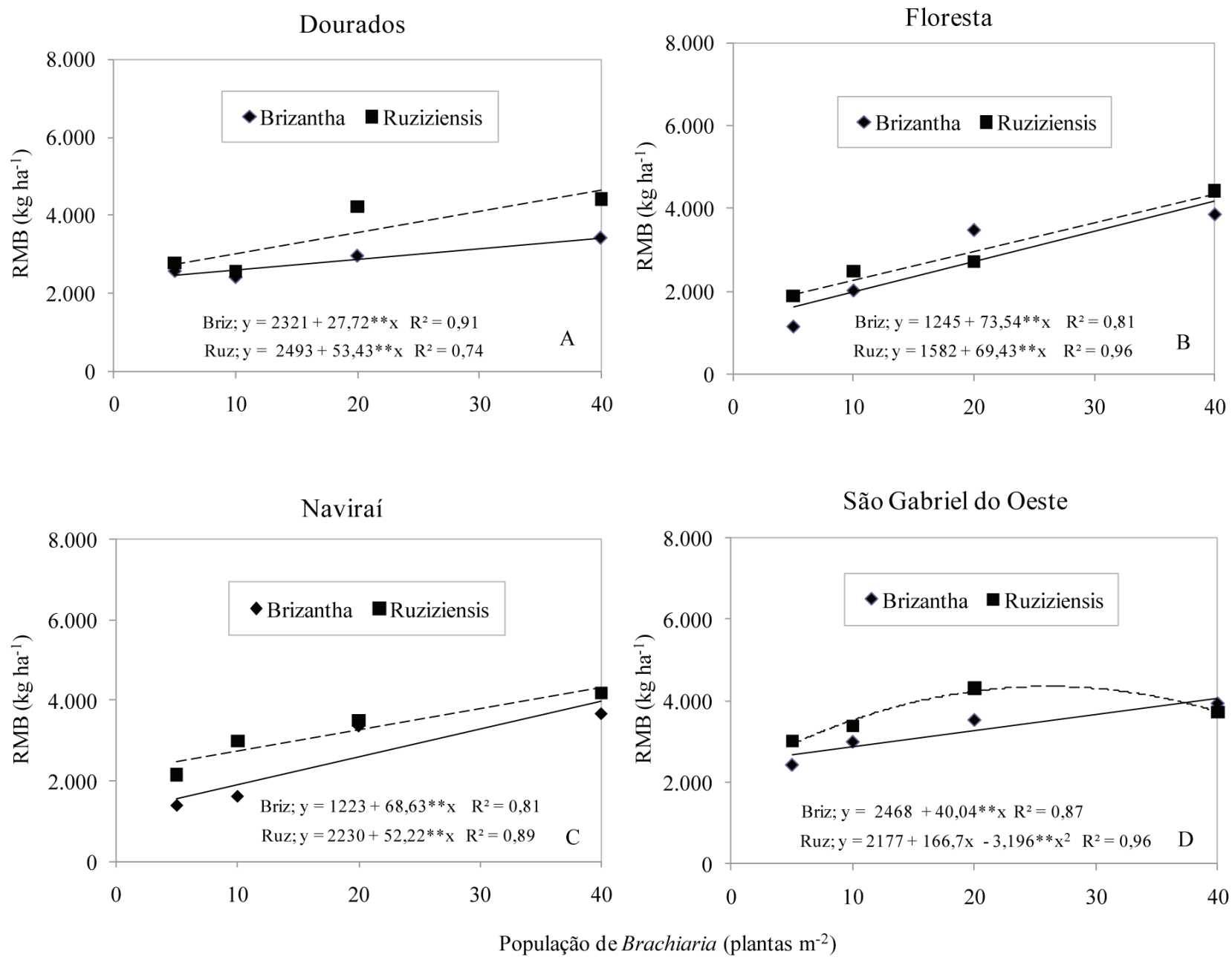

Figura 2 - Rendimento de massa seca de Brachiaria (RMB) consorciada com milho safrinha, em espaçamento reduzido, em Dourados (A), Floresta (B), Naviraí (C) e São Gabriel do Oeste (D). **(p<0,01).

em Dourados os resultados foram semelhantes para as espécies de Brachiaria (Figura 4A); no consórcio com $B$. brizantha, o máximo acúmulo de RTM foi com população de 9 plantas $\mathrm{m}^{-2}$ e mínimo com 31 plantas $\mathrm{m}^{-2}$, sendo $12.146 \mathrm{~kg} \mathrm{ha}^{-1}$ e $9.886 \mathrm{~kg} \mathrm{ha}^{-1}$ no consórcio com $B$. ruziziensis e $B$. brizantha, respectivamente. Para B. ruziziensis 11 plantas $\mathrm{m}^{-2}$ e para B. brizantha com 32 plantas $\mathrm{m}^{-2}$, com acúmulos de $12.588 \mathrm{~kg} \mathrm{ha}^{-1}$ e $9.826 \mathrm{~kg} \mathrm{ha}^{-1}$, respectivamente.
Nos demais ambientes, o consórcio com B. ruziziensis seguiu a tendência observada em Dourados. Em Floresta, proporcionou maior acúmulo de RTM, $7.041 \mathrm{~kg} \mathrm{ha}^{-1}$, na população de 10 plantas $\mathrm{m}^{-2}$ de $B$. ruziziensis, e menor, $5.600 \mathrm{~kg} \mathrm{ha}^{-1}$, na de 29 plantas $\mathrm{m}^{-2}$ (Figura 4B). Em Naviraí, verificou-se máximo acúmulo, $8.019 \mathrm{~kg} \mathrm{ha}^{-1}$, com 12 plantas $\mathrm{m}^{-2}$, e mínimo, $6.338 \mathrm{~kg} \mathrm{ha}^{-1}$, com 31 plantas $\mathrm{m}^{-2}$ (Figura 4C), e em São Gabriel do Oeste, o ponto máximo, $11.023 \mathrm{~kg}$ 
Dourados
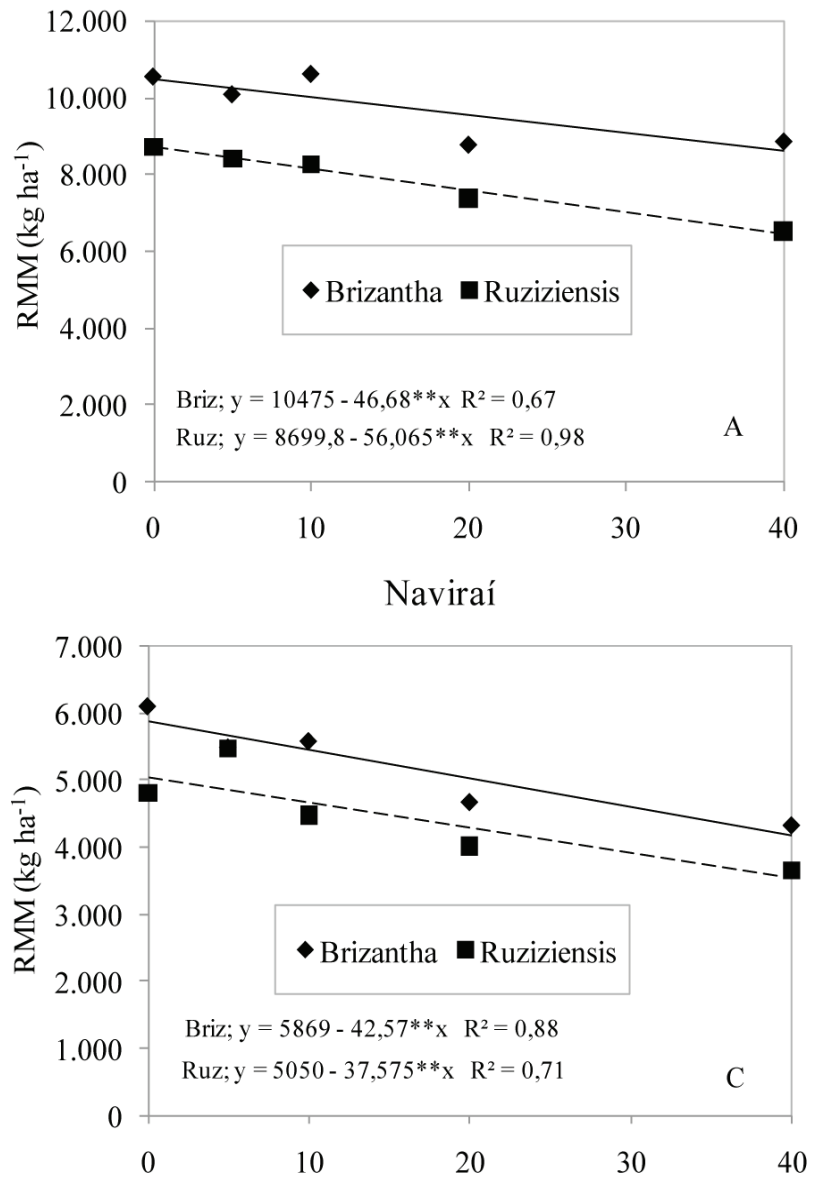

Floresta

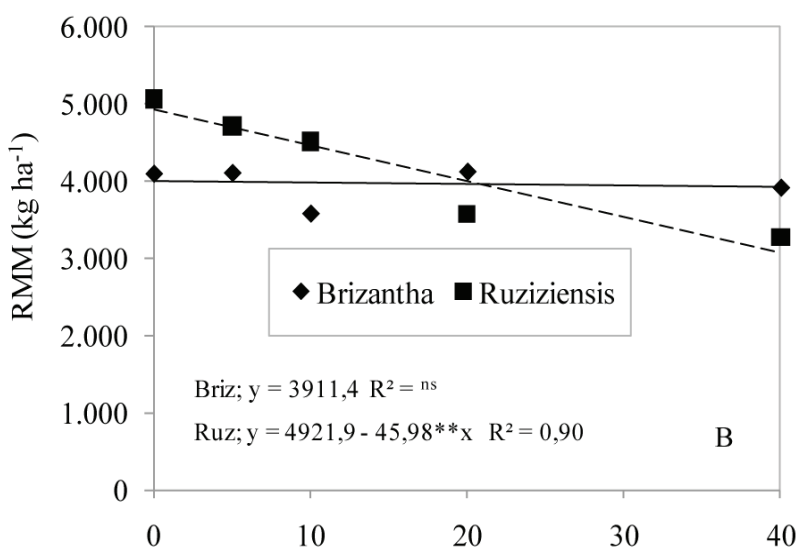

São Gabriel do Oeste

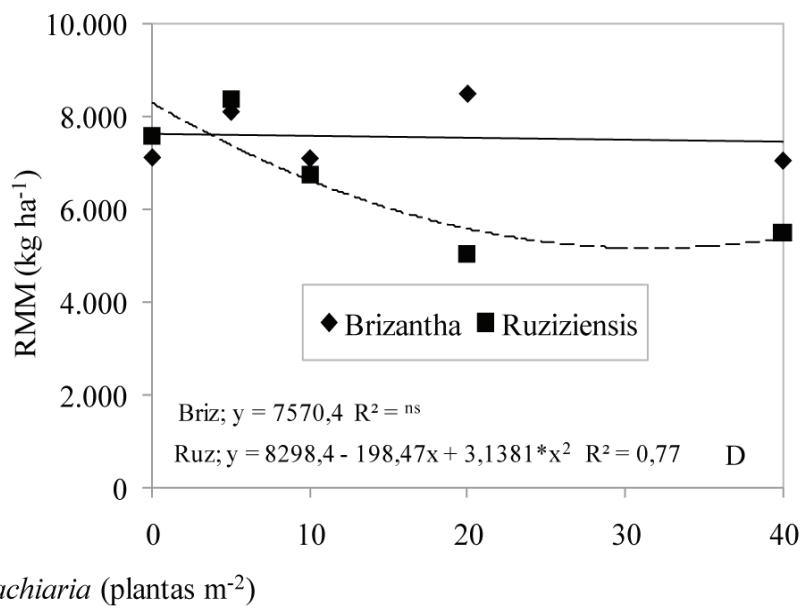

Figura 3 - Rendimento de massa seca de milho (RMM) consorciado com populações de Brachiaria, em espaçamento reduzido, em Dourados (A), Floresta (B), Naviraí (C) e São Gabriel do Oeste (D). **(p<0,01), $*(p<0,05)$ e ns não significativo.

ha ${ }^{-1}$, com 10 plantas $\mathrm{m}^{-2}$, e mínimo, $6.910 \mathrm{~kg} \mathrm{ha}^{-1}$, com 31 plantas $\mathrm{m}^{-2}$ (Figura 4D).

Os ajustes das equações matemáticas e consequentemente os resultados encontrados quando de RTM com $B$. brizantha foram diferentes nos ambientes estudados. No consórcio com $B$. brizantha no ambiente Floresta o máximo acúmulo de RTM, $7.974 \mathrm{~kg}$ $\mathrm{ha}^{-1}$, foi verificado com 33 plantas $\mathrm{m}^{-2}$ (Figura 4B); em São Gabriel do Oeste, observou-se máximo acúmulo,
$12.370 \mathrm{~kg} \mathrm{ha}^{-1}$, na população de 26 plantas $\mathrm{m}^{-2}$ (Figura 4D). Já em Naviraí houve aumento linear em função do incremento na população de plantas (Figura 4C). A variável massa seca (Figuras 2, 3 e 4) é de suma importância por representar a condição inicial para semeadura da cultura subsequente (Chioderoli et al., 2012). Este acúmulo de massa é influenciado pela espécie forrageira utilizada, pela população de plantas e também pelo ambiente, suas condições climáticas e 
Dourados

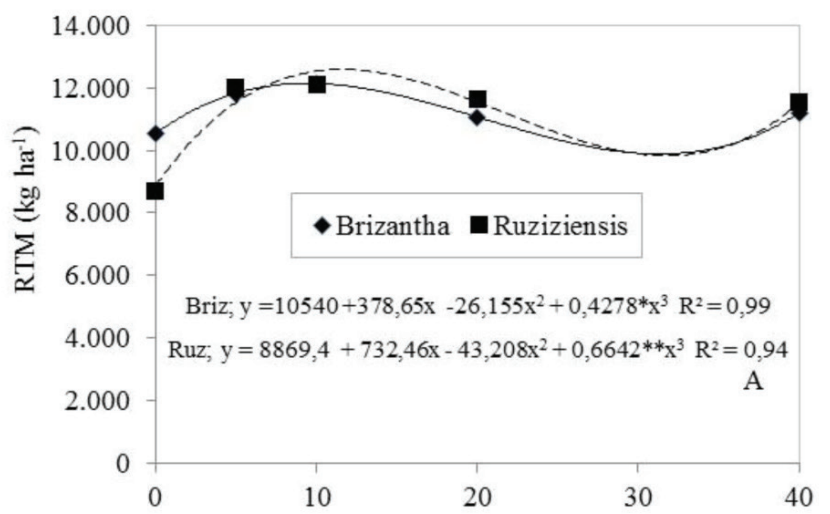

Naviraí

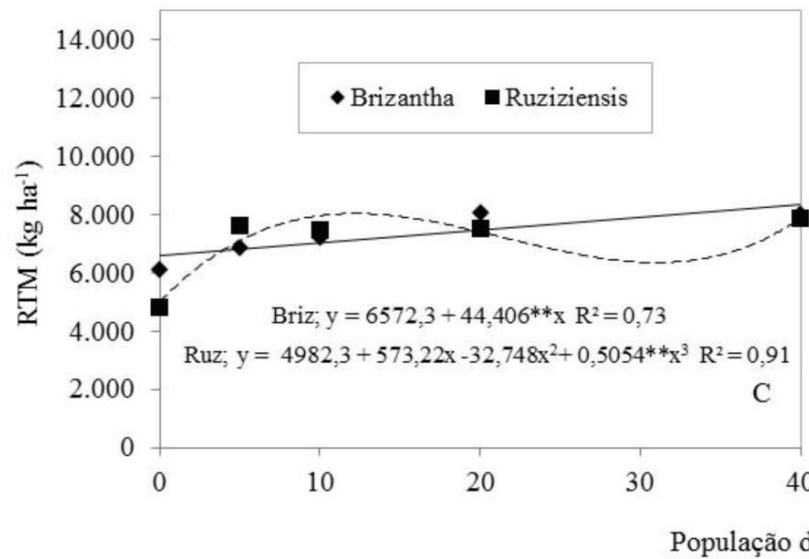

Floresta

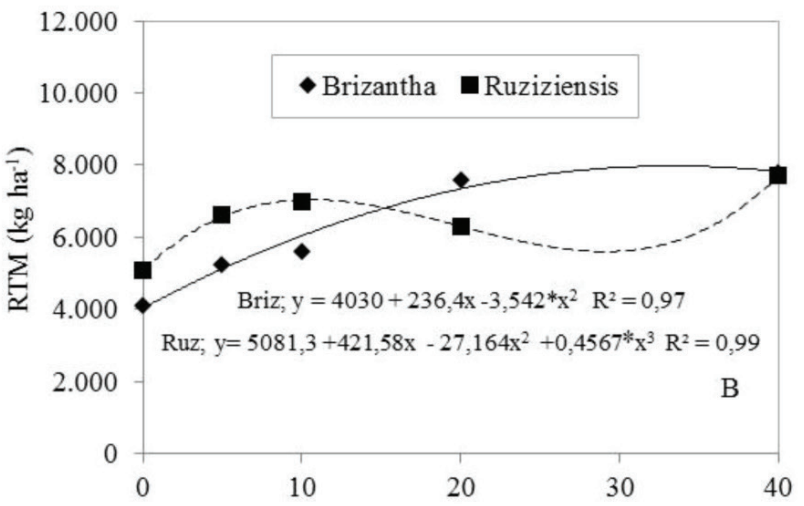

São Gabriel do Oeste

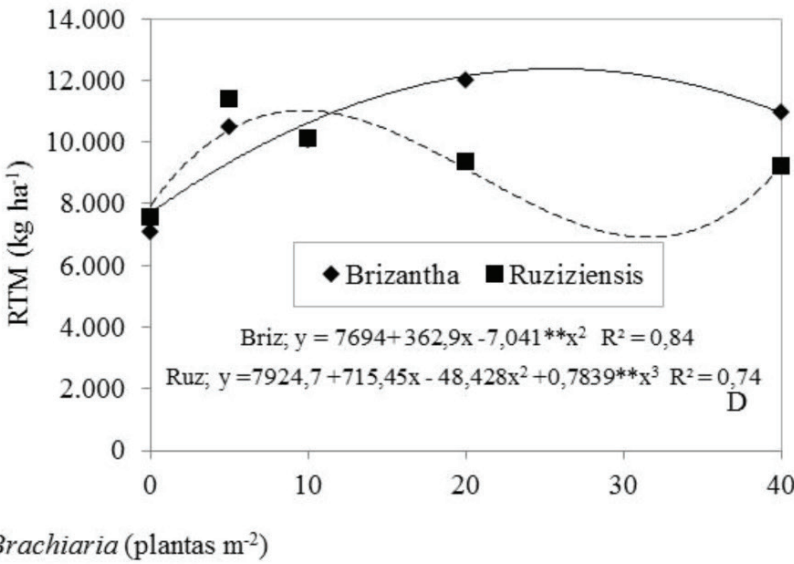

Figura 4 - Rendimento total de massa seca (RTM) do consórcio de milho safrinha com populações de Brachiaria, em espaçamento reduzido, em Dourados (A), Floresta (B), Naviraí (C) e São Gabriel do Oeste (D). $* *(p<0,01), *(p<0,05)$ e ${ }^{\text {ns }}$ não significativo.

de solo (Carvalho \& Amabile, 2006). Por isso essas respostas reforçam a importância de implantar e estudar este sistema em diferentes ambientes a fim de empregar essa tecnologia da melhor forma possível e escolher técnicas que proporcionem maior rendimento e retorno econômico, pois a produção de massa seca tem que estar ajustada com a produtividade de grãos.

Os tratamentos consorciados são opções para aumento do aporte de resíduos, proporcionando maior quantidade de massa seca total. Contudo, ocorre ne- cessidade de observar não só a quantidade de massa adicionada ao sistema, mas também a produtividade que será alcançada (Figura 5). O ponto de máximo acúmulo de massa seca nem sempre é o ideal, e sim aquele em que ocorre uma mínima redução na produtividade e boa quantidade de massa adicionada, o que se espera em consórcio com as menores populações de Brachiaria, afinal este cultivo é adensado em período de inverno, caracterizando uma competição mais intensa entre as espécies. 
A produtividade de grãos de milho também foi influenciada pelas populações das forrageiras, com maior produtividade no tratamento solteiro em relação aos consorciados (Figura 5). Em consórcio com $B$. brizantha ocorreu redução linear na produtividade de acordo com o aumento no número de plantas, atingindo decréscimos de $13,39 \mathrm{~kg} \mathrm{ha}^{-1}$ por planta $\mathrm{m}^{-2}$, conforme o modelo matemático obtido. No consórcio $\operatorname{com} B$. ruziziensis observou-se redução de $42 \mathrm{~kg} \mathrm{ha}^{-1}$ de grãos de milho por planta $\mathrm{m}^{-2}$, obtendo-se a mínima produtividade de $4.953 \mathrm{~kg} \mathrm{ha}^{-1}$ na população de 35 plantas $\mathrm{m}^{-2}$.

Esses resultados sugerem maior produtividade de grãos de milho utilizando-se a menor população possível de braquiária em consórcio. Isso se deve em parte às características das forrageiras e à competição que naturalmente existe entre as espécies. A B. ruziziensis forma uma pastagem densa, proporcionando rápida cobertura do solo (Pariz et al., 2011). O espaçamento reduzido $(0,45 \mathrm{~m})$ favorece o acúmulo de massa da forrageira (Ceccon et al., 2014), aumentando a competição.
Observou-se neste trabalho (Figura 2) que a $B$. ruziziensis produziu maior quantidade de massa seca que a $B$. brizantha, exceto em São Gabriel do Oeste, e afetou o rendimento de massa seca do milho (Figura 3). Assim, entende-se que a competição da cultura do milho com esta forrageira foi mais intensa, o que foi verificado nas situações de altas populações de plantas (Figura 5).

Brambilla et al. (2009) também verificaram interferência na produtividade do milho no sistema consorciado com espaçamento $0,45 \mathrm{~m}$ em relação ao cultivo solteiro, mas com utilização de altas quantidades de sementes da forrageira.

Ceccon et al. (2014) verificaram que o aumento na população de plantas de B. ruziziensis proporcionou aumento na massa seca total da forrageira, com redução na massa seca e produtividade de grãos de milho, ressaltando que o cultivo de milho safrinha em espaçamento reduzido demanda mais cuidados para ajustar a população de plantas da forrageira.

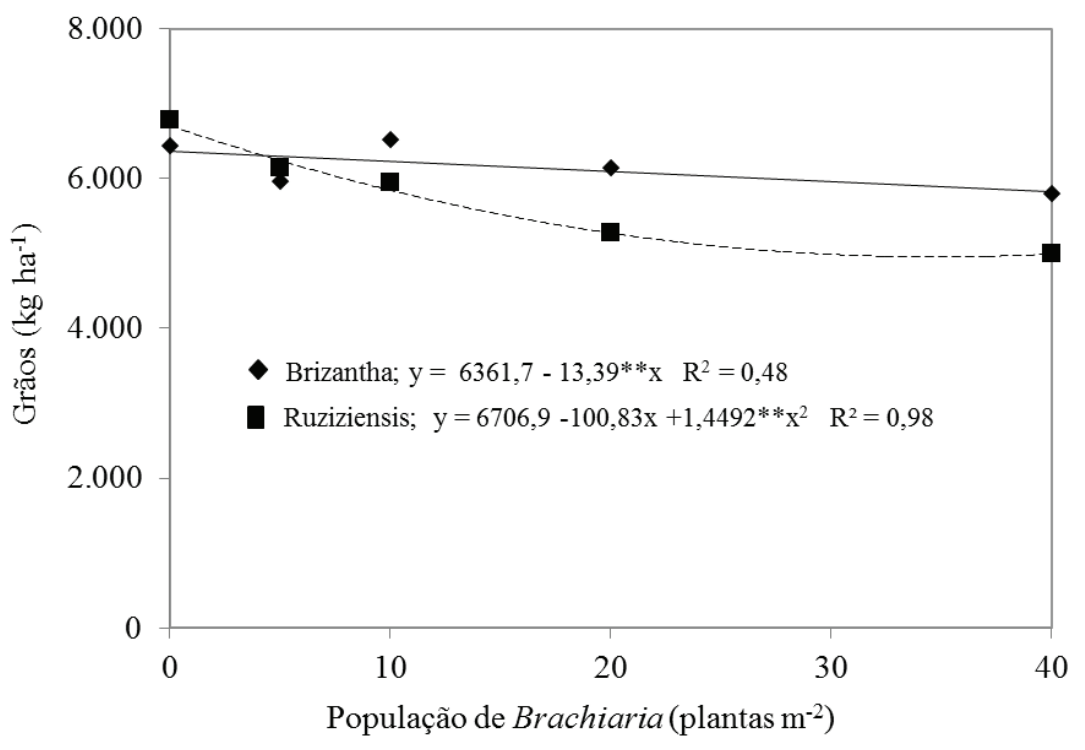

Figura 5 - Produtividade de grãos de milho (Grãos) cultivado em consórcio com populações de Brachiaria, em espaçamento reduzido. Médias de Dourados, Floresta, Naviraí e São Gabriel do Oeste. **(p<0,01). 


\section{Conclusões}

Os ambientes de cultivo e as populações de plantas de braquiária interferem na produtividade de massa seca e de grãos do milho safrinha e na produtividade de massa seca das duas espécies de braquiária avaliadas.

O milho apresenta redução linear na produtividade de grãos com aumento da população de plantas de $B$. brizantha e redução quadrática em função da população de $B$. ruziziensis.

O aumento na população de plantas de braquiária aumenta a sua produtividade de massa, mas reduz a produtividade de massa do milho.

O consórcio de milho safrinha com cinco plantas $\mathrm{m}^{-2}$ de $B$. ruziziensis ou de $B$. brizantha em espaçamento reduzido proporciona melhor rendimento de massa seca total e maior massa seca que o milho solteiro.

O consórcio é indicado como estratégia para cobertura de solo e/ou formação de pastagem, uma vez que os ganhos advindos deste sistema de cultivo podem compensar as perdas na produtividade do milho safrinha.

\section{Referências}

AMADO, T. J. C.; PONTELLI, C. B.; SANTI, A. L.; VIANA, J. H. M.; SULZBACH, L. A. de S. Variabilidade espacial e temporal da produtividade de culturas sob sistema plantio direto. Pesquisa Agropecuária Brasileira, Brasília, DF, v. 42, n. 8, p. 1101-1110, 2007. DOI: 10.1590/S0100-204X2007000800006.

ANDREOLA, F.; COSTA, L. M.; OLSZEVSKI, N. Influência da cobertura vegetal de inverno e da adubação orgânica e, ou, mineral sobre as propriedades físicas de uma terra roxa estruturada. Revista Brasileira de Ciência do Solo, Viçosa, MG, v. 24, n. 4, p. 857-865, 2000.

DOI: 10.1590/S0100-06832000000400017.

BORGHI, E.; CRUSCIOL, C. A. C. Produtividade de milho, espaçamento e modalidade de consorciação com Brachiaria brizantha em sistema plantio direto. Pesquisa Agropecuária Brasileira, Brasília, DF, v. 42, n. 2, p. 163 171, 2007. DOI: 10.1590/S0100-204X2007000200004.

BRAMBILLA, J. A.; LANGE, A.; BUCHELT, A. C.; MASSAROTO, J. A. Produtividade de milho safrinha no sistema de integração lavoura-pecuária, na região de Sorriso, Mato Grosso. Revista Brasileira de Milho e Sorgo, Sete Lagoas, v. 8, n. 3, p. 263-274, 2009.

DOI: 10.18512/1980-6477/rbms.v8n3p263-274.

CARVALHO, A. M.; AMABILE, R. F. Plantas condicionadoras de solo: interações edafoclimáticas, uso e manejo. In: CARVALHO, A. M.; AMABILE, R. F. (Ed.). Cerrado: adubação verde. Planaltina: Embrapa Cerrados, 2006. p. 143-170.

CECCON, G. Cálculo para taxa de semeadura de espécies forrageiras perenes em cultivos anuais. Revista Agrarian, Dourados, v. 8, n. 27, p. 39-46, 2015.

CECCON, G.; KURIHARA, C. H.; STAUT, L. A. Manejo de Brachiaria ruziziensis em consórcio com milho safrinha e rendimento de soja em sucessão. Revista Plantio Direto, Passo Fundo, v. 19, n. 113, p. 4-8, 2009.

CECCON, G.; SILVA, J. F. da; NETO, A. L. N.; MAKINO, P. A.; SANTOS, A. dos. Produtividade de milho safrinha em espaçamento reduzido consorciado com populações de plantas de Brachiaria ruziziensis. Revista Brasileira de Milho e Sorgo, Sete Lagoas, v. 13, n. 3, p. 326-335, 2014. DOI: 10.18512/1980-6477/rbms.v13n3p326-335.

CHIODEROLI, C. A.; MELLO, L. M. M.; HOLANDA, H. V.; FURLANI, C. E. A.; GRIGOLLI, P. J.; SILVA, J. O. R.; CESARIN, A. L. Consórcio de Urochloas com milho em sistema plantio direto. Ciência Rural, Santa Maria, v. 42, n. 10, p. 1804-1810, 2012.

DOI: $10.1590 / \mathrm{S} 0103-84782012005000073$. 
CONCENÇO, G.; CECCON, G.; CORREIA, I. V. T.; LEITE, L. F.; ALVES, V. B. Ocorrência de espécies daninhas em função de sucessões de cultivo. Planta Daninha, Viçosa, MG, v. 31, n. 2, p. 359-368, 2013. DOI: $10.1590 / \mathrm{S} 0100-83582013000200013$.

CRUZ, S. C. S.; PEREIRA, F. R. S.; BICUDO, S. J.; SANTOS, J. R.; ALBUQUERQUE, A. W.; MACHADO, C. G. Consórcio de milho e Brachiaria decumbens em diferentes preparos do solo. Acta Scientiarum Agronomy, Maringá, v. 31, n. 4, p. 633-639, 2009.

DOI: 10.4025 /actasciagron.v31i4.915.

FERREIRA, D. F. SISVAR: a computer statistical analysis system. Ciência e Agroecologia, Lavras, v. 35, n. 6, p. 1039-1042, 2011.

DOI: $10.1590 / \mathrm{S} 1413-70542011000600001$.

INSTITUTO NACIONAL DE METEOROLOGIA. Estações automáticas: gráficos. Brasília, DF, 2018. Disponível em <http://www.inmet.gov.br/portal/index. php? $\mathrm{r}=$ home $/$ page\&page $=$ rede_estacoes_auto_graf $>$. Acesso em: 19 jan. 2018.

JAKELAITIS, A.; SILVA, A. F.; PEREIRA, J. L.; SILVA, A. A.; FERREIRA, L. R.; VIVIAN, R. Efeitos de densidade e época de emergência de Brachiaria brizantha em competição com plantas de milho. Acta Scientiarum Agronomy, Maringá, v. 28, n. 3, p. 373378, 2006.

MARCHÃO, R. L.; BALBINO, L. C.; SILVA, E. M. da; SANTOS JÚNIOR, J. D. G.; SÁ, M. A. C. de; VILELA, L.; BECQUER, T. Qualidade física de um Latossolo Vermelho sob sistemas de integração lavoura-pecuária no Cerrado. Pesquisa Agropecuária Brasileira, Brasília, DF, v. 42, n. 6, p. 873-882, 2007.

DOI: $10.1590 / \mathrm{S} 0100-204 X 2007000600015$.
PACIULLO, D. S. C.; FERNANDES, P. B.; GOMIDE, C. A. M.; CASTRO, C. R. T.; SOBRINHO, F. S.; CARVALHO, C. A. B. The growth dynamics in Brachiaria species according to nitrogen dose and shade. Revista Brasileira de Zootecnia, Viçosa, MG, v. 40, n. 2, p. 270 276, 2011.

DOI: $10.1590 / \mathrm{S} 1516-35982011000200006$.

PARIZ, C. M.; ANDREOTTI, M.; AZENHA, M. V.; BERGAMASCHINE, A. F.; MELLO, L. M. M.; LIMA, R. C. Produtividade de grãos de milho e massa seca de braquiárias em consórcio no sistema de integração lavourapecuária. Ciência Rural, Santa Maria, v. 41, n. 5, p. 875882, 2011.

DOI: $10.1590 / \mathrm{S} 0103-84782011000500023$.

PERIN, A.; SANTOS, R. H. S.; URQUIAGA, S.; GUERRA, J. G. M.; CECON, P. R. Produção de fitomassa, acúmulo de nutrientes e fixação biológica de nitrogênio por adubos verdes em cultivo isolado e consorciado. Pesquisa Agropecuária Brasileira, Brasília, DF, v. 39, n. 1, p. 35-40, 2004. DOI: 10.1590/S0100-204X2004000100005.

RESENDE, A. V. de; SHIRATSUCHI, L. S.; FONTES, J. R. A.; ARNS, L. L. K.; RIBEIRO, L. F. Adubação e arranjo de plantas no consórcio milho e braquiária. Pesquisa Agropecuária Tropical,Goiânia,v.38,n.4,p.269-275,2008.

SANTOS, H. G. dos; JACOMINE, P. K. T.; ANJOS, L. H. C. dos; OLIVEIRA, V. A. de; LUMBRERAS, J. F.; COELHO, M. R.; ALMEIDA, J. A. de; CUNHA, T. J. F.; OLIVEIRA, J. B. de. Sistema brasileiro de classificação de solos. 3. ed. rev. e ampl. Brasília, DF: Embrapa, 2013. 353 p.

WINTERSTEIGER. Plotseed TC: semeadora de parcelas automotriz. Riede, [2011]. Disponível em: <http://www. wintersteiger.com/pt/Seedmech/Products/Product-Range/ Plot -seeders/43-Plotseed-TC > . Acesso em: 15 ago. 2014. 